\title{
Recurrent wheezing in very preterm infants
}

\author{
Dawn E Elder, Ronald Hagan, Sharon F Evans, Helen R Benninger, Noel P French
}

\begin{abstract}
Aims-To document the prevalence of, and identify risk factors for, recurrent wheezing treated with bronchodilators in the first year of life.

Methods-Parental history and neonatal data were collected prospectively in a regional cohort of very preterm infants (<33 weeks). Data on maternal smoking, siblings at home, breast feeding, respiratory symptoms, and hospital re-admissions were documented at 12 months.

Results-Outcome data were available for $525 / 560(95 \%)$ of survivors. The incidence of recurrent wheeze was $76 / 525(14.5 \%)$ in very preterm infants and $20 / 657(3 \%)$ in a cohort of term newborns. Significant risk factors for recurrent wheeze in very preterm infants were parental history of asthma, maternal smoking, siblings at home, neonatal oxygen supplementation at 28 days, 36, and 40 weeks of gestation. Conclusions-Wheezing respiratory illnesses are common in very preterm infants. The factors involved are similar to those in more mature infants, with the addition of immaturity and neonatal lung injury.

(Arch Dis Child 1996; 74: F165-F171)
\end{abstract}

Keywords: Very preterm, wheezing in infancy, bronchodilators, maternal smoking, asthma.

Recurrent respiratory illnesses, often requiring admission to hospital, are common in very preterm $(<33$ weeks gestation) or very low birthweight $(<1501 \mathrm{~g})$ infants in the first few years of life. ${ }^{1-3}$ Wheezing is a prominent symptom in a significant number of these episodes. In the general population several variables have been identified as risk factors for wheezing in infancy. ${ }^{4}$ These variables are also likely to be associated with wheezing in very preterm or very low birthweight infants.

These risk factors can be classified as arising temporally in the prenatal, perinatal, or postnatal stages of development. Prenatal factors, such as race or a family history of bronchial reactivity, have been studied in relation to neonatal chronic lung disease $\mathrm{e}^{5-7}$ but not in relation to later clinical respiratory outcomes in very immature infants. Perinatal factors such as maternal smoking during pregnancy, the period of gestation, low birthweight for gestation and acute and chronic neonatal lung disease have been analysed in relation to subsequent respiratory symptoms in very immature infants, though usually only in small birthweight delimited cohorts ${ }^{23-10}$ The contribution of postnatal factors such as social class, siblings in the home, male sex, maternal smoking and breast feeding has rarely been analysed in these cohorts ${ }^{9} 10$ though they are identified as being important in more mature infants.

In a large normal population of 5-11 year olds Rona et al found that shorter gestational age was associated with an increased risk of respiratory symptoms, especially wheeze, whereas low birthweight for gestation influenced only measured lung function in a manner that was independent of associated maternal smoking. ${ }^{11}$ This is an exceptional study in that it analysed separately the effects of gestation and the appropriateness of fetal growth. Other, retrospective, studies in childhood and adolescent populations have documented associations between both preterm birth, ${ }^{5}$ low birthweight ${ }^{12}{ }^{13}$ and the development of bronchial hyperreactivity.

The role of neonatal chronic lung disease has been studied in several preterm or VLBW cohort studies using both prospective and retrospective data ${ }^{238-10}$ Only two of these studies $^{910}$ looked at influences outside the neonatal period that may have modified respiratory outcome and in all but one, containing a small number of infants, ${ }^{10}$ the cohorts were birthweight defined and likely to contain a variable number of low birthweight for gestation infants. The sensitivity, specificity, and positive predictive value of various periods of neonatal supplemental oxygen requirement have been analysed and the suggestion made that the need for supplemental oxygen at 36 weeks of gestational age is the best predictor of abnormal pulmonary outcome. ${ }^{3}$ This time period for oxygen supplementation was thus suggested as a better definition for neonatal chronic lung disease than the more usual period of 28 days after birth. This study, however, did not measure the influence of known postnatal variables contributing to the adverse pulmonary outcomes.

No study has examined all these temporally unrelated risk factors in a cohort of very preterm infants to establish the association between gestational age and the development of wheezing in infancy, to examine the effects of differing patterns of fetal growth, and to investigate how these influence the effects of the variables identified in more mature infants.

The objectives of our study were firstly to document the respiratory outcome of a large cohort of very preterm infants in the first year of life, secondly to look for prenatal, perinatal, and postnatal influences on the respiratory outcome, and finally to examine the correlation between various periods of oxygen supplementation in the newborn period and later outcome. This study reports our findings with respect to the outcome of recurrent wheeze 
treated with bronchodilators occurring during the first year of life in this group.

\section{Methods \\ ESTABLISHMENT OF COHORT}

All infants $<33$ weeks of gestation, liveborn or cared for during 1990 and 1991 in King Edward Memorial Hospital for Women $(\mathrm{KEMH})$, the sole obstetric perinatal tertiary referral centre in Perth, Western Australia, were enrolled. ${ }^{14} 15$ This centre delivered and/or cared for $93 \%$ of the very preterm mother and infant groups born in Western Australia during the period, and for $96 \%$ of the survivors. All mothers were interviewed, their obstetric record reviewed, and information verified while the mother was still an inpatient. Gestational age was determined by the best obstetric estimation of maturity, with known maternal dates and confirmatory obstetric ultrasound examination before 20 weeks being the gold standard. Less than $5 \%$ of mothers had uncertain dates or no early ultrasound scan. In these cases clinical gestational age assessment of the newborn using the Ballard scales was used. ${ }^{16}$

\section{DATA COLLECTION}

Demographic and parental respiratory history

These were collected prospectively at birth and included maternal race, age, smoking during pregnancy and the presence of other siblings at home. Maternal smoking during pregnancy was scored quantitatively as $0,1-10$, or $>10$ cigarettes per day. A respiratory history questionnaire, based on the American National Institutes of Health respiratory questionnaire, ${ }^{17}$ was used to obtain a history of asthma or wheezing for both parents. Parents were assessed as having a positive history if they reported either doctor diagnosed asthma or a history of recurrent wheeze on exertion or exposure to cold at any time in childhood or adult life. Parental history was documented as being positive in none, one, or both parents.

\section{Neonatal history}

Prospectively recorded neonatal data included gestational age, birthweight, sex, the presence and severity of acute respiratory disease, days of ventilation, days on oxygen and method of feeding at discharge. Gestational age was recorded as completed weeks of pregnancy and grouped as: <27, 27-29, and 30-32 weeks. Smallness for gestational age was defined as a birthweight below the 10th centile on age and sex appropriate charts. ${ }^{18}$ Acute respiratory diseases were classified using the criteria of Hjalmarson. ${ }^{19}$ Hyaline membrane disease (HMD) was defined as respiratory distress with radiographic evidence of air bronchogram and a ground glass appearance of the lung fields with increasing oxygen requirements over the first 24-36 hours of life persisting to 48 hours in the absence of infection. ${ }^{19}$ Hyaline membrane disease was considered severe if the infant required ventilation with a mean airway pressure $\geqslant 10 \mathrm{~cm} \mathrm{H}_{2} \mathrm{O}$ and $\mathrm{FIO}_{2} \geqslant 80 \%$ in the first 48 hours of life. Infants with no respiratory distress, mild or transient respiratory distress, infection or immature lungs were classified as non-HMD. Exogenous surfactant was only used in the last six months of the cohort recruitment period. Chronic lung disease (CLD) was defined using the criteria of Bancalari as the need for supplemental oxygen after 28 days of life associated with clinical symptoms and an abnormal chest radiograph. ${ }^{20}$ Persistent oxygen requirement at 34 through 40 weeks of gestational age was documented.

\section{After discharge}

For the first six months after discharge the infant's primary carer was asked to keep a monthly diary documenting the method of feeding and any respiratory symptoms. A health questionnaire, completed at 12 months corrected age, was used to document and cross check the following:

respiratory symptoms using a grid, modified from that of Woodward et al, ${ }^{21}$ listing 13 respiratory symptoms and a frequency table graded in the following manner:

(a) never ( 0 bouts), rarely ( 1 bout), sometimes (2-4 bouts), frequently (more than 4 bouts) and constantly (most of the time);

(b) need for drug treatment for wheeze;

(c) a quantitative assessment of current parental smoking habits;

(d) the number of siblings in the home;

(e) total duration of breast feeding after discharge from the neonatal unit $(<1$ month, 1-2 months, 3-6 months, $>6$ months); and

(f) the number and nature of admissions to hospital in the first year of life.

Data for those infants admitted were checked against records at Princess Margaret Hospital, the State's only tertiary referral hospital for children. Supplementary information was also obtained by the neonatal follow up coordinator who was in regular contact with local child health workers.

\section{MAIN OUTCOME VARIABLES}

We have used recurrent wheeze treated with bronchodilators in the first year of life as our primary outcome measure. We defined this as the infant being reported as having two or more episodes of respiratory illnesses associated with wheezing for which the general practitioner or paediatrician prescribed a bronchodilator. This outcome was based on parental report that they perceived their infant wheezing. This was confirmed for those infants admitted to the Children's Hospital and in our hospital records for those who were seen regularly in our follow up clinic. We did not otherwise examine the infant to confirm the presence of wheezing nor assess its severity. No infant was known to have a cardiac or other mechanical cause for wheezing. We compared our figures with a local control population from the Western Australian Pregnancy Cohort Study. ${ }^{22}$ This is a healthy population of 2834 newborns being followed up from early pregnancy to late childhood, in 
Table 1 General clinical and demographic data

\begin{tabular}{|c|c|c|c|}
\hline Variable & No (\%) & Variable & No (\%) \\
\hline \multicolumn{2}{|l|}{ Gestational age (weeks): } & HMD† & $247(47 \cdot 0)$ \\
\hline$<27$ & $51(9 \cdot 7)$ & PPV & $298(56.8)$ \\
\hline $27-29$ & $143(27 \cdot 2)$ & $C L D^{\star \star}$ & $114(21 \cdot 7)$ \\
\hline $30-32$ & $331(63.0)$ & Oxygen at 36 weeks & $63(12 \cdot 0)$ \\
\hline \multicolumn{2}{|l|}{ Birthweight (g): } & Oxygen at 40 weeks & $21(4 \cdot 0)$ \\
\hline$<1001$ & $90(17 \cdot 1)$ & Breast feeding: & \\
\hline $1001-1500$ & $202(38 \cdot 5)$ & None & $154(29 \cdot 3)$ \\
\hline $1501-2000$ & $191(36 \cdot 4)$ & $<1$ Month & $49(9 \cdot 3)$ \\
\hline$>2000$ & $42(8 \cdot 0)$ & 1-2 Months & $53(10 \cdot 1)$ \\
\hline Birthweight $<10 \%$ & $167(31 \cdot 8)$ & 3-6 Months & $126(24 \cdot 0)$ \\
\hline Male sex & $286(54.5)$ & $>6$ Months & $143(27 \cdot 2)$ \\
\hline Caucasian & $449(85 \cdot 5)$ & Siblings at home & $274(52 \cdot 2)$ \\
\hline \multicolumn{2}{|l|}{ Parental $B H R^{\star}$ : } & Maternal smoking: & \\
\hline Neither parent & $390(74 \cdot 3)$ & None & $330(62 \cdot 9)$ \\
\hline One parent & $116(22 \cdot 1)$ & 1-10 per day & $75(14 \cdot 3)$ \\
\hline Both parents & $16(3 \cdot 0)$ & $>10$ per day & $120(22.9)$ \\
\hline
\end{tabular}

^Bronchial hyperreactivity (no information available for three infants), thyaline membrane disease, łpositive pressure ventilation, ${ }^{\star \star}$ chronic lung disease.

whom extensive information on pregnancy, health, development and respiratory outcomes are being collected. A time delimited subset of 657 have had their first year data analysed in relation to the frequency of wheezing episodes. We are unaware of any bias in our medical community to treat or not treat wheezing infants with bronchodilators if they have been very preterm. Those parents who themselves were using, or had recently used, bronchodilators were, however, more likely to discuss the need for bronchodilators in their infants when they attended our follow up clinic.

\section{STATISTICS}

All data were entered using the Statistical Analysis System (SAS) software package. ${ }^{23}$ Relations between variables and the outcome of bronchodilator treated wheezing were first assessed by means of $\chi^{2}$ analyses and calculation of univariate odds ratios. Logistic regression modelling was then used to evaluate the correlation between variables and wheezing while controlling for the effects of other confounding variables by the method of maximum likelihood. Adjusted odds ratios were calculated for each variable. These analyses were performed only in the very preterm cohort.

\section{Results}

There were 648 infants born $<33$ weeks gestation and cared for in KEMH during 1990-1. Twenty six died in the labour ward and 62 in the neonatal unit; 560 were discharged alive. Respiratory follow up was available on 532 $(95 \%)$ of these infants. Eight infants died in

Table 2 Univariate and multivariate odds ratios (OR) and $95 \%$ confidence intervals (95\% CI) of risk factors for wheeze treated with bronchodilators

\begin{tabular}{|c|c|c|}
\hline Variable & Univariate OR $(95 \% C I)$ & Adjusted OR $(95 \% \mathrm{CI})$ \\
\hline $\begin{array}{l}\text { BHR (any parent } v s \text { none) } \\
\text { Race (non-caucasian } v s \text { caucasian) } \\
\text { Male sex } \\
\text { Gestation }(<30 \mathrm{w} v s \geqslant 30 \mathrm{w}) \\
\text { Birthweight }<10 \% \\
\text { HMD } \\
\text { CLD } \\
\text { Oxygen at } 36 \text { weeks } \\
\text { Oxygen at } 40 \text { weeks } \\
\text { Maternal smoking (any } v s \text { none) } \\
\text { Siblings at home (any } v s \text { none) } \\
\text { Breast feeding ( } \geqslant 1 \text { month } v s<1 \text { month) }\end{array}$ & 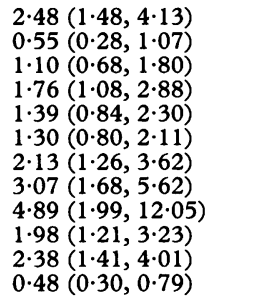 & 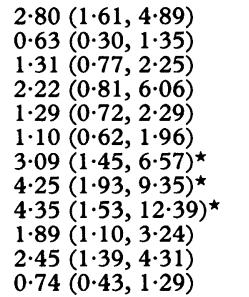 \\
\hline
\end{tabular}

*Each duration of oxygen requirement entered separately into the logistic regression. the first year of life. Causes of death were as follows: bronchiolitis (three cases, one a child with adrenoleucodystrophy), sudden infant death syndrome (two cases), and one case each of necrotising tracheitis, Leigh's syndrome, and gastroenteritis. One of these infants died near the end of the first year of life and her data were included in the analysis. Five hundred and twenty five infants were thus available for analysis and their clinical and demographic data are outlined in table 1 In those infants who died in the neonatal unit $12(20 \%)$ had no respiratory questionnaire data. Ten $(20 \%)$ of the remainder had a positive family history for asthma in one or other parent.

Bronchodilator treatment was prescribed for recurrent wheeze in $76(14.5 \%)$ infants. Recurrent episodes, defined as two or more, of wheeze both treated and untreated occurred in $125(23.8 \%)$ infants. Admission to any hospital because of a respiratory illness associated with wheezing was required by $78(14.8 \%)$ of infants and of these 39 never received bronchodilator treatment. In the reference control group of 657 term infants during the first year of life, 20/657 (3.0\%) infants had wheeze that was treated with bronchodilators and $21 / 657(3 \cdot 2 \%)$ experienced wheeze requiring admission to any hospital (W Macdonald, personal communication).

Significant risk factors for wheeze requiring bronchodilators on univariate analysis in our very preterm cohort were lower gestational age ( $<30$ weeks), oxygen requirement at 28 days (CLD), oxygen requirement at 36 weeks and at term, the presence of siblings at home, maternal smoking and a parental history of bronchial hyperreactivity (table 2) Breast feeding was protective.

Logistic regression analysis, controlling for all significant univariate risk factors, showed that a parental history of bronchial hyperreactivity, the presence of siblings in the home, maternal smoking, CLD and oxygen requirement at 36 weeks and term remained significant risk factors for wheeze requiring bronchodilators (table 2).

Parental history of bronchial hyperreactivity (BHR) and maternal history of smoking showed an incremental dose-response relation to wheeze requiring bronchodilators on univariate analysis. Eleven per cent (43/390) of infants without a family history of BHR wheezed for which bronchodilators were required; $17 \%(20 / 116)$ with one parent positive for BHR and $69 \%(11 / 16)$ with both parents positive also required bronchodilator treatment. One BHR positive parent increased the risk of wheeze to 1.7 (95\% CI $1.3,2.3)$, while two BHR positive parents positive increased the risk to $17 \cdot 8(95 \%$ CI $10 \cdot 1,31 \cdot 2)$.

Table 3 shows the relations between maternal smoking, duration of breast feeding after discharge, and wheeze treated with bronchodilators in the first year of life. Overall, there is a dose-response to maternal smoking, with the incidence of wheeze increasing as the daily number of cigarettes smoked by the mother increases. In non-smokers any duration of breast feeding decreased the incidence of treated wheeze. In both moderate (1-10 per 
Table 3 Number of infants (\%) with wheeze treated with bronchodilators by maternal smoking and breast feeding exposure

\begin{tabular}{lllllll}
\hline & \multicolumn{2}{l}{ Breast feeding } & & & \\
\cline { 2 - 7 } & Nil & $<1$ Month & $1-2$ Months & 3-6 Months & $>6$ Months & Total \\
\hline No smoking & $16 / 82(19 \cdot 5)$ & $3 / 24(12 \cdot 5)$ & $1 / 32(3 \cdot 1)$ & $5 / 89(5 \cdot 6)$ & $12 / 103(11 \cdot 6)$ & $37 / 330(11 \cdot 2)$ \\
$1-10$ Per day & $3 / 24(12 \cdot 5)$ & $3 / 11(27 \cdot 3)$ & $1 / 4(25 \cdot 0)$ & $3 / 15(20 \cdot 0)$ & $2 / 21(9 \cdot 5)$ & $12 / 75(16 \cdot 0)$ \\
$>10$ Per day & $13 / 48(27 \cdot 1)$ & $3 / 14(21 \cdot 4)$ & $5 / 17(29 \cdot 4)$ & $4 / 22(18 \cdot 2)$ & $2 / 19(10 \cdot 5)$ & $27 / 120(22 \cdot 5)$ \\
Total & $32 / 154(20 \cdot 8)$ & $9 / 49(18 \cdot 4)$ & $7 / 53(13 \cdot 2)$ & $12 / 126(9 \cdot 5)$ & $16 / 143(11 \cdot 2)$ & $76 / 525(14 \cdot 5)$ \\
\hline
\end{tabular}

day) and heavy smokers ( $>10$ per day), it was only with prolonged breast feeding $(>6$ months) that a protective effect was seen with no increased incidence of wheeze occurring in this group of infants whose mothers smoked.

Only a small number of infants had mothers who smoked solely either during pregnancy or after pregnancy, but not in both periods (table 4). There was no significant difference in outcome for their infants between infancy exposure and in utero exposure. In all analyses the exposure to maternal smoking in infancy was the variable examined.

To measure whether any particular period of prolonged oxygen requirement in the neonatal period was a better predictor of our wheeze outcome, we calculated the sensitivity, specificity, positive predictive values, negative predictive values and accuracy of varying durations of oxygen requirement after birth (table 5) The points chosen were oxygen requirement at 28 days (CLD) and weekly incremental increases in duration of oxygen supplementation from 34 weeks to 40 weeks gestational age. These were analysed using univariate data so that comparison with the figures of Shennan et al could be made. ${ }^{3}$ The sensitivity for each duration is low and decreases with increasing length of oxygen requirement. The highest positive predictive value occurs in those infants oxygen dependent at term. The positive predictive value for wheeze requiring bronchodilators is no better for those infants requiring oxygen treatment at 36 weeks than it is for those requiring oxygen at 28 days.

We calculated the per cent concordance for the different logistic regression equations for each weekly increase in length of oxygen requirement, from 34 to 40 weeks inclusive, and oxygen requirement at 28 days of age. Overall, about $75 \%$ of the babies were correctly assigned as developing or not developing wheeze. There was little difference in any specific duration of oxygen supplementation, suggesting, therefore, that no particular duration of neonatal oxygen dependency is a better predictor of recurrent wheeze requiring bronchodilators than any other (table 5)

Table 4 Outcome for infants exposured to maternal smoking solely during pregnancy or solely during infancy

\begin{tabular}{|c|c|c|c|c|}
\hline & Total & $\begin{array}{l}\text { Treated } \\
\text { wheeze }\end{array}$ & $\begin{array}{l}\text { Relative } \\
\text { risk }\end{array}$ & $95 \% C I$ \\
\hline \multirow{2}{*}{$\begin{array}{l}\text { No exposure } \\
\text { Pregnancy alone } \\
\text { Infancy alone } \\
\text { Pregnancy and } \\
\text { infancy }\end{array}$} & $\begin{array}{r}300 \\
30 \\
32\end{array}$ & $\begin{array}{r}34(11 \cdot 3 \%) \\
3(10 \cdot 0 \%) \\
5(15 \cdot 6 \%)\end{array}$ & $\begin{array}{l}0.88 \\
1.38\end{array}$ & $\begin{array}{l}0.29,2 \cdot 70 \\
0.58,3 \cdot 27\end{array}$ \\
\hline & 163 & $34(20.9 \%)$ & 1.84 & $1 \cdot 19,2 \cdot 84$ \\
\hline
\end{tabular}

Relative to no exposure.
When infants with any history of parental BHR, exposure to passive smoking, CLD in the neonatal period or cohabitation with siblings were excluded, the overall incidence of wheeze treated with bronchodilators in the remaining very preterm infants was $5 / 95$ $(5 \cdot 3 \%)$. This is still higher (difference $2 \cdot 2 \%$ $(95 \%$ CI -2.5 to $6.9 \%)$ ) than in the term infants.

\section{Discussion}

Wheezing is a common symptom in the first year of life in this population of infants born at less than 33 weeks of gestation. We restricted our risk analysis to those infants requiring bronchodilator treatment for wheeze to avoid including those infants wheezing only once as part of an identifiable viral illness such as bronchiolitis. The role of bronchodilators in the treatment of wheeze in infants in the first year of life is controversial, hence the lack of treatment in this age group may reflect varying medical practice rather than severity of the disease. This could have led us to both underand over-reporting of clinically important wheeze. The incidence of wheeze treated with bronchodilator in our very preterm cohort was almost five times higher than in our term control group. We did not examine these infants and are thus dependent on local practitioners for accuracy of diagnosis. However, both preterm and term control populations had their diagnosis ascertained in an identical manner.

We selected this as our measure of an adverse respiratory outcome, because it is the most commonly reported adverse respiratory outcome. $^{2810}$ There is also evidence that suggests that VLBW and very preterm infants have increased asthma ${ }^{24}$ and troublesome cough $^{25}$ later in life. A number of infants who wheeze during infancy will develop asthma later in childhood. ${ }^{26} \mathrm{We}$ are following up this cohort through their early school years.

Significant risk factors for wheeze treated with bronchodilators identified in our very preterm infants are similar to those identified in infants in the general population. ${ }^{4}$

Comparability of reported figures for wheeze outcome is compromised because of variations in definitions of wheeze and in the ages at which follow up has been documented. An increased incidence of wheeze symptoms in preterm compared with term infants has been found in birthweight defined cohort studies ${ }^{2} 8$ but no group has yet reported this outcome in a gestational age based cohort. Ford et al found that $40.9 \%$ of VLBW infants had experienced one or more wheezing episodes by the age of 2 
Table 5 Assessment of predictive value of various durations of oxygen dependence for the outcome of wheeze treated with bronchodilators

\begin{tabular}{|c|c|c|c|c|c|c|}
\hline & Sensitivity & Specificity & $P P V^{\star}$ & NPV† & Accuracy & Concordance \\
\hline $\begin{array}{l}\text { CLD }{ }^{\alpha} \\
\text { Oxygen }\end{array}$ & $\begin{array}{c}25 \cdot 0 \ddagger \\
\text { weeks): }\end{array}$ & $90 \cdot 2$ & $30 \cdot 2$ & $87 \cdot 7$ & 80.9 & $74 \cdot 4$ \\
\hline $\begin{array}{l}34 \\
35 \\
36 \\
37 \\
38 \\
39 \\
40\end{array}$ & $\begin{array}{l}30 \cdot 3 \\
27 \cdot 6 \\
25.0 \\
19.7 \\
15.8 \\
14.5 \\
11.8\end{array}$ & $\begin{array}{l}80 \cdot 4 \\
87 \cdot 3 \\
90 \cdot 2 \\
89 \cdot 8 \\
91 \cdot 8 \\
92 \cdot 9 \\
97 \cdot 3\end{array}$ & $\begin{array}{l}20 \cdot 7 \\
22 \cdot 6 \\
30 \cdot 2 \\
24 \cdot 6 \\
24 \cdot 5 \\
25 \cdot 6 \\
42 \cdot 9\end{array}$ & $\begin{array}{l}87 \cdot 2 \\
87 \cdot 3 \\
87 \cdot 7 \\
86 \cdot 9 \\
86 \cdot 6 \\
86 \cdot 5 \\
86 \cdot 7\end{array}$ & $\begin{array}{l}73 \cdot 1 \\
75 \cdot 8 \\
80 \cdot 8 \\
79 \cdot 6 \\
80 \cdot 8 \\
81 \cdot 5 \\
85 \cdot 0\end{array}$ & $\begin{array}{l}73 \cdot 9 \\
74 \cdot 1 \\
74 \cdot 1 \\
73 \cdot 8 \\
73 \cdot 4 \\
73 \cdot 4 \\
73 \cdot 6\end{array}$ \\
\hline
\end{tabular}

${ }^{\alpha}$ Chronic lung disease, ${ }^{*}$ positive predictive value, fnegative predictive value, fall figures are percentages.
We could find no effect of low birthweight for gestation, as measured by birthweight $<10 \%$. This is similar to the results of Rona et $a,^{11}$ who found that clinical symptoms were related to immaturity but that pulmonary function changes related to low birthweight for gestation.

A family history of asthma increases the likelihood of bronchial hyperresponsiveness in early infancy. ${ }^{30}$ While this association is also true for low birth weight infants $<2000 \mathrm{~g}$, ${ }^{928}$ the relation between a parental history of bronchial hyperreactivity and the outcome of wheeze has not been documented in a gestational age based cohort. We also had clear evidence of an incremental increase in risk when both parents reported symptoms of bronchial hyperreactivity and this effect persisted after controlling for all confounding variables in our logistic regression analysis. Some authors have postulated that familial bronchial hyperresponsiveness might be a risk factor for idiopathic preterm labour and chronic lung disease postnatally. ${ }^{31} 32$ This correlation with neonatal chronic lung disease may relate to an increase in severity in the disease in those infants with a family history of bronchial hyperresponsiveness ${ }^{57}$ rather than an increase in the prevalence.

Our rate of maternal smoking is comparable with that of other studies, although rates do vary considerably, partly depending on maternal race. ${ }^{33} 34$ We used parental report to gauge smoking exposures as this has been shown by others to be reliable. ${ }^{35}$ While the effect of maternal smoking on infant lung function may be most profound when the infant has been exposed in utero, ${ }^{36}$ exposure to environmental tobacco smoke in the first years of life seems to have a separate and significant effect on risk for respiratory illness and hospitalisation, especially in low birthweight infants. ${ }^{30} 3537$ This effect seems to be more severe in children with a predisposition to asthma or wheeze. ${ }^{38}$ In our cohort maternal smoking was a major contributing factor, almost doubling the risk of the infant developing wheeze requiring treatment. In infants of mothers who smoke during pregnancy a variety of pulmonary abnormalities have been reported and they may have a role in the development of bronchial hyperreactivity in preterm infants with chronic lung disease. ${ }^{34} 39$ 40-42 We were unable to differentiate the effects of in utero and infancy exposure, because we had so few mothers who smoked solely either during pregnancy or after delivery.

The presence of siblings in the home or sharing a room has been reported to have variable effects on the risk of wheezing illnesses in infancy. 12334344 We did not quantitate the number of siblings in the home, but there was an increased risk of wheeze in those infants with any sibling at home. This may relate to increased transmission of mild viral infections that are associated with wheezing in infancy whether or not there is bronchial hyperreactivity.

Neonatal chronic lung disease is known to be associated long term with bronchial hyperreactivity. ${ }^{29} 45$ Our study confirms this. We did the first year of life. There was no further increase in risk at the lowest extreme of gestational age in our cohort. 
not demonstrate a significant incremental increase in risk if oxygen requirement persisted beyond 34 weeks gestation. Definitions of neonatal chronic lung disease should have some long term predictive value, as suggested by Shennan et $a l^{3}$ yet there is no accepted concept of adverse pulmonary outcome. We have taken the single outcome measure of recurrent wheezing treated with bronchodilators rather than the definition of adverse pulmonary outcome used in Shennan's study which was very broad. One of their adverse outcomes was requirement for oxygen at 40 weeks gestational age - part of the spectrum of duration of supplemental oxygen for chronic lung disease. We found that no particular duration of oxygen supplementation was a better predictor than any other for our adverse outcome. This is in contrast to Sheenan et al, who reported that requirement for oxygen at 36 weeks gestation was the best predictor of abnormal pulmonary outcome. ${ }^{3}$ Shennan's study, which was birthweight based, did not control for the influence of other factors such as parental bronchial hyperreactivity and passive smoking. Sensitivity and specificity values calculated on univariate analyses are thus likely to present an incomplete and inaccurate picture.

The overall protective effect of breast feeding against the development of wheeze did not persist after controlling for other factors. Lucas et al showed in their group of preterm infants weighing less than $1850 \mathrm{~g}$ that early exclusive feeding of breast milk did not protect against the development of wheezing. ${ }^{46}$ In term infants a protective effect has been reported only in the first 4 months of life, though breast feeding has been reported as protective against the negative effect of maternal smoking on risk of respiratory illness ${ }^{1247}$ Our data suggest that this is true as we found a protective effect from prolonged breast feeding in infants of heavy smokers.

Wheezing illnesses are common in very preterm infants during their first year of life and the factors associated with an increased risk are similar to those reported in the general population. Immaturity, as measured by gestational age, and the acute lung injury that commonly accompanies immaturity are associated with a higher risk. Low birthweight for gestation is not associated with an increase in risk. This study has again highlighted at least one modifiable factor that may decrease the incidence of wheeze in this group. This is maternal smoking which in this cohort occurred in $37 \cdot 1 \%$. We found that many women who stop smoking in pregnancy often restart in the postnatal period. This critical time must be used for support and education to help mothers prolong their period of non-smoking. Further advances in the prevention and treatment of neonatal chronic lung disease may also improve respiratory outcome in this group and we have yet to see the long term effects of early surfactant use. Little can be done to ameliorate the effects of the presence of siblings in the house or a parental history of bronchial hyperreactivity, but awareness of these risk factors may encourage earlier diagnosis and appropriate treatment of preterm infants presenting with wheeze in the first year of life.

We are grateful to Chris Campbell, Debra Chiffings, Doreen Coakes and Judith Onslow, who assisted with data collection and entry, and to Colleen Ryan who assisted with data entry. This study was funded by the Foundation for Women's and Infant's Health, King Edward Memorial Hospital, West Australian Health Promotion Foundation (Healthway).

1 Cunningham CK, McMillan JA, Gross SJ. Rehospitalization for respiratory illness in infants of less than 32 weeks gestation. Pediatrics 1991; 88: 527-32.

2 Ford GW, Rickards AL, Kitchen WH, Lissenden JV, Ryan MM, Keith CG. Very low birthweight and normal birthweight infants: a comparison of continuing morbidity. Med $\mathcal{F}$ Aust 1986; 145: 125-8.

3 Shennan AT, Dunn MS, Ohlsson A, Lennox K, Hoskins EM. Abnormal pulmonary outcomes in premature infants: prediction from oxygen requirement in the neonatal period. Pediatrics 1988; 82: 527-32.

4 Morgan WJ, Martinez FD. Risk factors for developing wheezing and asthma in childhood. Ped Clin North Am 1992; 39: 1185-203.

5 von Mutius E, Nicolai T, Martinez FD. Prematurity as a risk factor for asthma in preadolescent children. $\mathcal{F}$ Pediatr 1993; 123: 223-9.

6 Palta M, Gabbert D, Weinstein MR, Peters ME. Multivariate assessment of traditional risk factors for Multivariate assessment of traditional risk factors for
chronic lung disease in very low birth weight neonates. chronic lung disease in veriatr 1991; 119: 285-92

7 Hagan R, Minutillo C, French N, Reese A, Landau L, Le Souef $P$. Neonatal chronic lung disease, oxygen dependency and a family history of asthma. Pediatr Pulmonol 1995; 20: 277-83.

8 Greenough A, Maconochie I, Yuksel B. Recurrent respiratory symptoms in the first year of life following preterm delivery. $\mathcal{F}$ Perinat Med 1990; 18: 489-94.

9 Lucas A, Brooke OG, Cole TJ, Morley R, Bamford MF. Food and drug reactions, wheezing, and eczema in preterm infants. Arch Dis Child 1990; 65: 411-15.

10 Myers MG, McGuinness GA, Lachenbruch PA, Koontz FP, Hollingshead R, Olson DB. Respiratory illnesses in survivors of infant respiratory distress syndrome. Am Rev Respir Dis 1986; 133: 1011-18.

11 Rona RJ, Gulliford MC, Chinn S. Effects of prematurity and intrauterine growth on respiratory health and lung function in childhood. $B M G$ res

12 Weitzman M, Gortmaker S, Sobol A. Racial, social and environmental risks for childhood asthma. Am $\mathcal{f}$ Dis Child 1990; 144: 1189-94.

13 Schwartz J, Gold D, Dockery DW, Weiss ST, Speizer FE. Predictors of asthma and persistent wheeze in a national sample of children in the United States. Am Rev Respir Dis 1990; 142: 555-62.

14 Hagan R, Benninger H, Chiffings D, Evans S, French $N$. Very preterm birth: A regional study. 1 . Maternal and obstetric factors. Br f Obstet Gynaecol 1996; 103: 230-8.

15 Hagan R, Benninger H, Chiffings D, Evans S, French N. Very preterm birth: A regional study. 2 . The very preterm infant. Br f Obstet Gynaecol 1996; 103: 239-45.

16 Ballard JL, Novak KK, Driver MA. A simplified score for assessment of fetal maturation of newly born infants. assessment of fetal maturatio

17 Ferris BG. Epidemiology standardization project. Am Rev Respir Dis 1978; 118: 1-120.

18 Blair E, Stanley FJ. Intra-uterine growth charts. Australian Government Publishing Service, Canberra: 1985

19 Hjalmarson O. Epidemiology and classification of acute, neonatal respiratory disorders. Acta Pcediatr Scand 1981; 70: 773-83.

20 Bancalari E, Abdenour GE, Feller R, Gannon J. Bronchopulmonary dysplasia: Clinical presentation. f Pediatr 1979; 95: 819-23.

21 Woodward A, Douglas RM, Graham NMH, Miles H. Acute respiratory illness in Adelaide children: breast feeding modifies the effect of passive smoking 7 Epidemiol Comm Health 1990; 44: 224-30.

22 Newnham JP, Evans SF, Michael CA, Stanley FJ, Landau LI. Effects of frequent ultrasound during pregnancy: a randomised controlled trial. Lancet 1993; 342: 887-91.

23 SAS Institute. SAS/STAT user's guide. Release 6.03. Cary, North Carolina: SAS institute, 1988.
Notitute.

24 Seidman DS, Laor A, Gale R, Stevenson DK, Danon YL. Is low birthweight a risk factor for asthma during adolescence? Arch Dis Child 1991; 66: 584-7.

25 Chan KN, Elliman A, Bryan E, Silverman M. Respiratory symptoms in children of low birth weight. Arch Dis Child 1989; 64: 1294-304.

26 Martinez FD, Wright AL, Taussig LM, Holberg CJ, Halonen M, Morgan WJ, and the Group Health Medical Associates. Asthma and wheezing in the first six years of life. N Engl f Med 1995; 332: 133-8.

27 Kitchen WH, Ford GW, Doyle LW, Rickards AL, Kelly EA. Health and hospital readmissions of very-low-birthweight and normal-birth-weight children. Am $\mathcal{F}$ Dis Child 1990; 144: 2213-18.

28 Chan KN, Noble-Jamieson CM, Elliman A, Bryan EM, Aber VR. Airway responsiveness in low birthweight Aber VR. Airway responsiveness in low birthweight
children and their mothers. Arch Dis Child 1988; 63: 905-10.

29 Northway WH, Moss RB, Carlisle KB, Parker BR, Popp $\mathrm{R}$ L, Pitlick PT, et al. Late pulmonary sequelae of 
bronchopulmonary dysplasia. $N$ Engl f Med 1990; 323: 1793-9.

30 Young S, Le Souëf PN, Geelhoed GC, Stick SM, Turner $\mathrm{KJ}$, Landau LI. The influence of a family history of , Landaut early infancy. $N$ Engl f Med 1991; 324: 1168-73.

31 Nickerson BG, Taussig LM. Family history of asthma in infants with bronchopulmonary dysplasia. Pediatrics 1980; 65: $1140-4$.

32 Bertrand J-M, Riley SP, Popkin J, Coates AL. The longterm pulmonary sequelae of prematurity: the role of familal hyperreactivity and the respiratory distress syndrome. N Engl f Med 1985; 312: 742-5.

33 Wright AL, Holberg C, Martinez FD, Taussig L and Grou Health Medical Associates. Relationship of parental moking to wheezing and nonwheezing lower respiratory tract illnesses in infancy. $\mathcal{F}$ Pediatr 1991; 118: 207-14.

34 Hanrahan JP, Tager IB, Segal MR, Tosteson TD, Castille RG, Van Vunakis $\mathrm{H}$, et al. The effect of maternal smoking during pregnancy on early infant lung function. $\mathrm{Am} R e v$ Respir Dis 1992; 145: 1129-35.

35 Chilmonczyk BA, Salmun LM, Megathlin KN, Neveux LM Palomaki GE, Knight GJ, et al. Association between exposure to environmental tobacco smoke and exacerbations of asthma in children. $N$ Engl $₹ \mathrm{Med} 1993$; 328: 1665-9.

36 Taylor B, Wadsworth J. Maternal smoking during pregnancy and lower respiratory tract illness in early life. Arch Dis Child 1987; 62: 786-91.

37 Chen Y. Environmental tobacco smoke, low birth weight, and hospitalization for respiratory disease. Am f Respir Crit Care Med 1994; 150: 54-8.

38 Sherrill DL, Martinez FD, Lebowitz MD, Holdaway MD, Flannery EM, Herbison GP, et al. Longitudinal effects of passive smoking on pulmonary function in New Zealand children. Am Rev Respir Dis 1992; 145: 1136-41.

39 Collins MH, Moessinger AC, Kleinerman J, Bassi J, Rosso $\mathrm{P}$, Collins AM, et al. Fetal lung hypoplasia associated with morphometric analysis. Ped Res 1985; 19: 408-12.

40 Chen MF, Kimizuka G, Wang NS. Human fetal lung changes associated with maternal smoking during pregchanges associated with maternal smo

41 Johnson DE, Lock JE, Elde RP, Thompson TR Pulmonary neuroendocrine cells in hyaline membrane disease and bronchopulmonary dysplasia. Ped Res 1982; 16: 446-54

42 Aguayo SM. Determinants of susceptibility to cigarette smoke. Am $\mathcal{F}$ Respir Crit Care Med 1994; 149: 1692-8.

43 Gardner G, Frank AL, Taber LH. Effects of social and family factors on viral respiratory infection and illness in the first year of life. $\mathcal{F}$ Epidemiol Comm Health 1984; 38: 42-8.

44 Woodward A, Douglas RM, Graham NMH, Miles H. Acute respiratory illness in Adelaide children - the influence of child care. Med f Aust 1991; 154: 805-8.

45 Silva DT, Hagan R, Sly PD. Home oxygen therapy for neonatal chronic lung disease in Western Australia. $\mathcal{F}$ Paediatr Child Health 1995; 31: 185-8.

46 Lucas A Brooke OG, Morley R, Cole TJ, Bamford MF. Early diet of preterm infants and development of allergic or atopic disease: randomised prospective study. $B M F$ or atopic disease:

47 Wright AL Holberg CJ, Martinez FD, Morgan WJ, Taussig LM and Group Health Medical Associates. Breast feeding and lower respiratory tract illness in the first year of life. $B M F$ 1989; 299: 946-9. 